\title{
Employee Engagement in Multinational Diverse Organization in Difficult Terrain: A Study of Non-
} Family Station Organization

\author{
Clarisse Blazi ${ }^{1}$, Olawumi D. Awolusi² \\ 1 University of Roehampton, London, UK \\ ${ }^{2}$ Kampala International University, Kampala, Uganda \\ clarisse.blazi@roehampton-online.ac.uk, awolusi.olawumi@kiu.ac.ug
}

\begin{abstract}
Engagements and commitments of many expatriates are often determined by several socioeconomic, demographic, cultural, environmental and organizational factors. These issues faced by employees in duty stations like United Nations Mission in Darfur (UNAMID) often have telling effects on their work. Consequently, the broad objective of this study was to assess the influence of the working environment on foreign job commitment in UNAMID. The study applied "a mixed-method research approach", utilizing both "qualitative and quantitative research" strategies, with a sample size of 100 respondents from the United Nations Peace Keeping Mission in Darfur, Northern Sudan. Specifically, questionnaires and in-depth Interview were the main instruments. Findings from the quantitative studies showed no significant relationship between employee disengagement, work terrain, job stress, communication, socio-cultural factors and expatriate's job commitment in UNAMID. While for the qualitative analysis, it was reported that there are both negative and positive effects of working in another country. The study, therefore, concludes that employee disengagement, job stress, working terrain, communication and socio-cultural factors are not associated, with expatriate's job commitment in UNAMID. It is therefore recommended that organizations should develop organizational peculiar plans and programs that would help cushion the physical and psychological effect of new working terrain on expatriates for them to be able to be effective, productive and be able to eventually achieve the ultimate goal of their deployment to the new work station.
\end{abstract}

Keyword: Employee engagement; Multinational diverse organization; mixed research; Non-family station organization.

\section{Introduction}

Employee engagement has been described as a concept that is difficult to define and succinctly explained even though it is a topic that has so much flooded articles in Human Resources and Management press in recent years. Despite many scholars and researchers giving their definition to it, there is no consensus on the definition of employee commitment (Soldati, 2007) as some researchers have described it as a concept that has many meanings depending on context (Dajani, 2015). It is worth noting that staff member comment is very important to the business and commercial success of any organization as well as in achieving whatever goal an organization has set out to achieve because engaged employees are like the backbone of an organization. As far back as the early eighteenth century, engagement of employees outside their home terrain has been in place and it continues to date. The modern economy demands employees' engagement in terrains different from that which they are used to, leading. The quantitative data were analyzed using the chi-square test, while qualitative data were analyzed using thematic analysis.

To movements of persons temporarily from their places of origin to more nations around the world (Bonache, 2005; Gupta and Gupta, 2012). With this increasing globalization of businesses and commercial activities, this movement of employees from their terrain to other places is now a general test for many employees around the world (Bhatti et al., 2012; Bonache, 2005). Moving out of one's terrain or home country could have significant effects on an individual and is not without difficulties and challenges (Bonache, 2005) especially when such an individual has a problem adjusting to the new environment (Bhatti et al., 2012). These effects in literature could range from culture shock while at the duty station or upon return (Bonache, 2005), family and social tensions, loss of status, homesickness (Hack-Polay, 2012), physical stress and psychological stress (Subramaniam, 2017). All these could affect employee productivity as research has found a significant connection between the rise employee engagement and growing of selling.

In several organizations (Merry, 2013) this expatriate adjustment has been abstracted as the extent of adjustment, experienced by the individual or the level of comfort, familiarity, and ease that the individual 
feels toward the new environment (Gupta and Gupta, 2012). Such ability for an expatriate to work in a new environment depends on adaptation and adjustment in new surroundings, relatives' effect, the facility to communicate with a workmate and being open to the new community (Zainol et al., 2014). The non-family duty stations are duty stations classified by the International Civil Service Commission (ICSC) as when the United Nations Department for Safety and Security (UNDSS) decides that eligible respondents of expatriate workers are restricted from being present at the duty station for six months or longer most times (UNOPS, 2016) usually because it is too dangerous for the immediate families to stay. An employee is deemed to be engaged when he/she meets the set objectives and meets job expectations (Meyer, 2017). A staff member committed to work has operational effectiveness (Bhuvanaiah and Raya, 2015) which enable a business to increase as well as employee satisfaction. For a context like that of this current study, expatriates have their engagements and commitments to duty determined by several socio-economic, demographic, cultural, environmental and organizational factors.

These issues faced by employees in duty stations like UNAMID thereby have telling effects on their work. Studies have attempted to explore some of the factors associated with employee engagement but few have studied in the context of a duty station like UNAMID. This broad objective of the paper tested the influence of the working environment on foreign job commitment in UNAMID. The study area is characterized hostile with hotness by harsh and adverse heat during the day and extreme cold during winter. Sampled population come from countries within the equatorial zones and has not been exposed to such environmental conditions. Also, the militarization of the region provides an environment where expatriates are taken hostage qualifying the study area a difficult terrain (Haslberger \& Brewster, 2009). There is a considerate difference in productivity and feeling of engagement between employees in a perfect working environment and employees working in difficult terrains as observed by (Mawritz et al., 2014). As a typical example "United Nations staff at the headquarters in New York" is not commonly exposed to threats that we face in the field missions. There is a diverse population in the workplace and there are 121 nationalities identified on the ground. The language barrier, beliefs, spiritual practices and social association which have at times negatively escalated into the unwanted scenario is a prominent feature of the study terrain.

Staff commitment is vital to the progress of a company (Subramanian, 2017), especially expatriates who are engaged in the operations of an organization in a new environment. Foreign workers are important in promoting experiential learning as well as injecting new thinking into the organization. However, adjustment and adaptation of these expatriates to a new environment could be challenging and could have negative effects on the performance of the organization. Some of the challenges expatriates' faces include stress, the tendency of less productivity, lack of motivation and feeling homesick due to separation from families, friends, and relatives leading to underperformance and operational inefficiency. Studies have shown that many human resources managers lack the needed strategies to address these challenges. Wide aspiration of the research is to test the effect of the working environment on expatriate job commitment. The working environment is defined in the context of 1 . Employee disengagement; 2. Job stress; 3. Working terrain; 4. Communication; and 5. Social-cultural environment (culture, religious practices and social association). The research focuses on the "United Nations Peacekeeping Mission in Darfur", a hardship duty station where expatriate from several places is deployed. Though they earn a good salary, the place has several trials which need managers to address (Collings et al., 2011) so that they perform successfully.

This could partly be because expatriates are seen as affluent, comfortable, preferred and even mostly viewed as very important persons. The broad objective of this study was to assess the influence of the working environment on foreign job commitment in UNAMID. However, the specific objectives of the study include:

- To investigate the effect of employee disengagement on expatriates' job commitment in "United Nations Peacekeeping Mission in Darfur".

- To assess the effect of job stress on expatriates' Job commitment in "United Nations Peacekeeping mission in Darfur".

- To examine the effect of working terrain on expatriates' job commitment in "United Nations Peacekeeping Mission in Darfur".

- To investigate the influence of communication on expatriate' job commitment in "United Nations Peacekeeping Mission in Darfur". 
- To examine the effect of social-cultural environment on expatriate' job commitment in "United Nations Peacekeeping mission in Darfur".

To achieve the above-stated objectives, the following questions were contrived:

- What is the influence of employee disengagement on expatriates' job commitment?

- What is the influence of job stress on expatriates' job commitment?

- What is the effect of working terrain on expatriates' job commitment?

- What is the influence of communication on expatriate' job commitment?

- What is the effect of the social-cultural environment on expatriate' job commitment?

Also, based on the above objectives, questions, and conceptual literature, the following hypotheses were tested in the quantitative segment of this study:

$\mathbf{H O}_{1}$ : there is no significant relationship between employee disengagement and expatriates' job commitment in United Nations Peacekeeping Mission in Darfur.

$\mathbf{H O}_{2}$ : there is no significant relationship between job stress and expatriates' job commitment in United Nations Peacekeeping mission in Darfur.

$\mathbf{H O}_{3}$ : there is no significant relationship between working terrain and expatriates' job commitment in United Nations Peacekeeping mission in Darfur.

$\mathbf{H O}_{4}$ : there is no significant relationship between communication and expatriate' job commitment in "United Nations Peacekeeping Mission in Darfur".

$\mathbf{H O}_{5}$ : there is no significant relationship between social-cultural environment on expatriate' work commitment in "United Nations Peacekeeping Mission in Darfur".

Studies on foreign professionals working in a hardship area are less if any although the literature on employee engagement seems to be replete (Dajani, 2015; Merry, 2013; Soldati, 2007). Due to some of the challenges that expatriates face in new environments particularly in difficult terrains including Darfur, Sudan, there is the need to explore several issues that affect their engagement, welfare, happiness, performance, commitment, and causes of stress to develop strategies to mitigate them. Employees are vital to the growth and profitability of any organization. Therefore, this study is enthusiastic about contributing to the body of knowledge regarding diverse angle such as emotional aspects to employees working in a foreign country as well as attempt to inform policies, programs, organizational strategies purposed at addressing these challenges faced by these expatriates.

\section{Review of Related Literature}

Conceptual and Theoretical Reviews: There has been an insufficient study on staff member commitment, which hampered the advancement and adoption of theories in the study of employee engagement. However, an extensive search of the literature reveals that one of the theories that have been used to explain employee engagement and participation in workplaces is the integrated theory of staff member commitment. In light of the integrated theory of employee engagement, the theory seeks to explain that there are different types of engagement and that job demand and incomes influence the emotional situation of the employees which in the end affect engagement. The employee engagement theory categorizes engagement into four namely; obligation engagement i.e. the responsibilities an employee perform; assignment management i.e. employees have diverse occupations at work and can have varying levels of engagement; organization engagement i.e. the employee can be approximately engaged in their organizations nevertheless of their work engagement, and team engagement i.e. employees may not fully commit in teamwork despite being highly engaged in their work. Furthermore, the level of engagement is affected by the different levels of physical conditions, job resources and demands as well as the engagement type.

Another theory that has been used to underpin most studies on employee work engagement is the job demand resources model (Remo, 2012), which postulates that the main human motivation is directed towards the maintenance and accumulations of incomes. It, however, has its origins in other theories and underlying combining high job demands with low job control can result in work stress and sickness. The key 
tenets state that employees who take the decision personally to meet their job demands do not experience work stress. Furthermore, another theory that has been cited in the literature is the Kahn's theory of employee engagement which he developed in his qualitative study on the emotional situation of personal engagement and disengagement at the workplace. He found that the three psychological conditions associated with engagement or disengagement at work include meaningfulness, safety and availability. Social exchange theory (SET) argues that obligations and duties are generated through a series of interactions between parties who are in a state of reciprocal interdependence e.g. employer-employee kind of interaction. The theory points out that relationship evolves into trusting, loyal and mutual commitments as long as the parties abide by certain rules of exchange (Cropanzo and Mitchell, 2005).

Employee engagement is deemed as an essential and comes with several benefits for an organization including higher productivity, greater enthusiasm and better commitment for the greater benefit of the organization as a whole. Some of the conceptual frameworks that have been used in literature to underpin and studies on employee engagement include but not limited to; Social Exchange Theory proposed by Shah (2006:213) which states that "obligations are made through a series of interactions between parties who are in a state of reciprocal interdependence. It is give and take relationship and perceived fairness between the two parties which dictates how successful the relationship is. It was argued that the level of engagement of the employees is largely dependent upon the facilities and resources which they receive from their organization". Secondly, based on the social exchange theory, Kang (2014: 23) "has developed his conceptual model of employee engagement. According to the Kang model of employee engagement, psychological capital and perceived service climate influence the level of employee engagement in the organization".

Employee Engagement: Employees are valuable people to any organization, and with more innovative products and precise amenities. Additionally, excellent abilities are needed, especially at a time when the human resource market has become more competitive as a result of globalization. The commitment of employees to organizations highly affects their performance as well as the performance of the organization. It is, however, important to note that all these numerous sources define engagement to some degree by its outcomes and as something given by the employee which can benefit the organization. There is a consensus that engaged employees to feel a sense of attachment towards their organization, focusing not only in their role but in the organization as a whole (Robertson-Smith and Markwick, 2009). (Gallup, 2006, cited, in Robertson-Smith and Markwick, 2009) have identified three types of employees based on their level of engagement; engaged employees who work with enthusiasm and have an intense relationship with their enterprise, driving the transformation of the business toward the front. The next group is the not-engaged group, they are essentially "checked out". They are sleepwalking through their workday, putting time- but not energy or passion- into their work. Daily, these employees destabilize the job undertake by their colleagues.

Empirical Review: Expatriate and other Staff commitment at the workplace and associated factors. This section presents some of the findings on the factors that might affect the commitment level of expatriate staff at the workplace or better duty stations in line with the topic of this research. The availability of global markets provide an environment for companies to extend their borders beyond their country of origin and send expatriates to abroad affiliates, it explains the need and the importance for expatriates (Nunes et al., 2016). Expatriates face several challenges in their new place of assignment which affects the performance of their duties and organizational commitment. The last group are known as disconnected staff members who are dissatisfied when performing the job and also execute the sorrow in them. Expatriates commitment to duty is important to the achievement of the goals and objectives of their organization at the duty station. Several studies in the literature have found several factors affecting the level of commitment a staff to the duty assigned him/ her in an organization as well as how well these staffs become engaged in what the organization does, ranging from individual to the job or organizational characteristics.

Commitment to corporate social responsibility is one of the numerous factors that have also been identified in the literature as an important facilitator of employee participation and commitment to duty. When organizations demonstrate a considerable level of dedication to enhance the human being environments, is to give more sense and importance to staff, clients and partner as well, which is to inspire commitment in employees by perceiving the significance of difference that commitment makes (Levinson, 2007b). Another factor that has been found to drive employee engagement and commitment is the availability of development opportunities in their (employee) current assignment. The importance of development opportunities in 
enabling engagement for development has been encouraged by many organizations (Robertson-Smith and Markwick, 2009). In another study by Melcrum, (2007), it was established that occasion for the improvement of job, training and progress, was the key element of engagement. In the same vein, (Khan and Atlaf, 2015, cited in Zainol et al., 2016) reported that outcomes of a study in Pakistan showed a positive correlation between employee engagement and training and development. According to (Tahir et al., 2014) in their study also examined the relationship between training and development, and employee's performance and productivity, the outcomes of their survey noted a significant relationship between the two variables. In a study in the United States, it was found that employees with high career aspirations needs, satisfied by the organization where they work are more likely to be better engaged and more committed to their duties in that organization (Moulik and Mazumdar, 2012).

In another study by (Rashid et al., 2011) which investigated the factors influencing employee engagement and relation of employee engagement to organizational and personal performance in the banking sector of Pakistan. Data collected from 250 employees in private commercial banks with questionnaires and analyzed using various statistical techniques showed an insignificant relationship between employee engagement and training and career development, and it can be concluded from their study that employee engagement and training and career development are not related. Pay (remuneration), reward and working hours have been cited in the literature as important for employee engagement and commitment to duty; "the importance of compensation, benefits and formal recognition in instilling employee engagement" (Melcrum, 2007). In Kenya, a study by Mokaya and Kipyegon, (2014) sought to determine the influence of remuneration package on employee engagement and it was eventually found that there exists a strong positive correlation between remuneration package and employee engagement. Also, (Mokaya and Kipyegon, 2014) concluded that of all the variables examined as determinants of employee engagement including performance management, personal development and growth, workplace recreation and remuneration package, remuneration was the highest contributor of employee engagement while workplace recreation was the lowest contributor. A further search of the literature on the importance of reward to employee commitment and performance to duty at the workplace, it was found by (Hijry and Haleem, 2017) in their study on the factors that influence employee performance in the steel factory in Saudi-Arabia, that majority of the respondents agreed that reward and compensation benefit affect the performance of employees.

In the same vein majority of the respondents agreed that salaries and perks are appreciated by employees as a veritable influence of rewards on a commitment to duty on the part of the staff of an organization (Khalid et al., 2016). Specifically, Khalid et al. (2016) study highlights factors affecting organizational commitment among bank Staff in Pakistan. The study found that the higher the organizational reward, the higher the organizational commitment, in the regression analysis, it was revealed that if the organizational reward was increased by $1 \%$, the level of commitment will be enhanced by $2 \%$. In a study by Dale Carnegie \& Associates, they set out to study the functional and emotional elements that may affect employee engagement, their findings reveal three key drivers of employee engagement, these factors include; the relationship of the employees with immediate supervisor, belief in senior leadership and pride in working for the company. Even the employees in the study said that it is the personal; relationship with their immediate supervisor that is the key to their commitment and engagement in their duties (Carnegie, 2012). As for the supervisor, research has also found that there is a relationship between commitment and supervisor support. In a study in Pakistan, it was found that, if the organizational supports are increased by $1 \%$, the level of staff commitment will be increased by $2 \%$ (Khalid et al., 2016). The study concluded that to enhance the commitment of employees, organizations should enhance the relevant factors.

Which include; organizational supports, organizational rewards, career development opportunities, favourable job conditions. While on the other hand from the findings of Dale Carnegie \& Associates, contrary to what some other studies have found, gender, ethnicity and work status (full time/part-time) do not emerge as critical variables of employee engagement (Carnegie, 2012). Work environment and employees commitment have also received the attention of researchers, in the work of (Njenga et al., 2015), it was submitted that there was a strong relationship between work environment and employees commitment. (Nunes et al., 2016) in a study in Brazil among expatriates have also explored some of the factors associated with expatriate commitment and performance, the factors they considered include; cultural intelligence and cross-cultural adaptation. In their study, they set out to test three hypotheses, one of the most important one 
was to determine whether there exists a significant and positive relationship between cultural intelligence and expatriate performance, the result of the study rejected the hypothesis and it was concluded that there is no significant positive relationship between cultural intelligence and performance of the employees. Another hypothesis that was considered in the study deals with the association between cross-cultural adaptation and expatriate performance, the hypothesis was not rejected and it was concluded that expatriate performance was related to cross-cultural adaptation (Nunes et al., 2016).

Furthermore, a study in Malaysia attempted to investigate the effects of dynamic intercultural competency of cultural intelligence and its dimensions on expatriate job performance, found a significant relationship between meta-cognitive cultural intelligence and job performance of the expatriates (Rose et al., 2010). The study which was conducted in a culturally diverse setting in Malaysia extended findings in other places to show that meta-cognitive capabilities are important for effective job performance and as expected, the behavioural dimension of cultural intelligence positively related to job performance. The explanation given for this in the report was that those with a high level of behavioural cultural intelligence tend to be flexible in their verbal and non-verbal behaviors to meet the expectation of others (Rose et al., 2010). Also, the level of availability that an employee at work is influenced by their resources, their recovery during leisure time and extra moral activities; highly stressful jobs with very little flexibility or autonomy has also been found to be associated with employee engagement and the commitment of employees to their duties. For expatriate staff, homesickness has been identified as one of the factors that could significantly affect the performance of their duty and being unable to meet organizational goals. It was further explained that being away from families and relatives do have psychological and physiological effects on the expatriate workers which have a lot of bearing on their engagement in their work (Hack-Polay, 2012).

One of the psychological challenges faced by expatriate staff and international workers in the engagement and discharge of their duties is culture shock, which has been described by (Kohls, 1979, cited in Rajasekar and Renand, 2013). This is one of the major challenges faced by expatriates, as most of them are not briefed about the culture of the host country. This could in a way affect their chances of settling into the new environment with new languages, food, and clothing and if they are unable to settle down well and quickly, this would affect their performance on their assignment. The research by (Rajasekar and Renand, 2013) has been able to reinforce that understanding the influence of national culture is critical to the effectiveness of business executives' foreign assignments. Also, it has been mentioned in the literature that the success of implementing overseas assignment does not solely depend on technical expertise; there are non-technical issues involved too such as culture, family, work procedures, and ability to interact with colleagues at work, adaptability and openness to local culture all exert influence on the assignment committed to these expatriates. In the work by (H. Zainol et al., 2014), using factor analysis, the findings of the study found the factors that loaded on work adjustment of expatriates, task satisfaction in the new post was the most important factor that influenced work adjustment and overall performance at the new job. The other factor that loaded significantly on work adjustment for the expatriate is the reward.

Causes of Stress for Employees: The term strain is utilized in so many manners nowadays, which leads to sickness during day time, to worry, and causes unhappiness. It has been demonstrated technically that it has a bad and good implication for employees. In the framework of this statement, the strain will only be considered as having a negative impact and will be dealt with within the framework of the workplace. Stress is not a health impairment but is the first sign of a harmful physical and emotional response that workers experience especially in environments that are challenging (ILO, 2016). The definition of stress and the terminology to refer to psychosocial hazards and risks at the workplace has changed over the years. The type of job a person has and the working conditions he or she is exposed to will affect the person's health (Doyle et al., 2005). The workplace environment is one of the important parts in our daily lives which cause a great deal of stress for employees in various sectors across the world. In the present era of globalization, where companies from different nationalities are trying to capture new markets and trying to make their presence known in many parts of the world, it is essential to have workers in foreign lands as an expatriate. This expatriate workers in the attempt to become engaged and perform on their assigned duty become stressed up having a negative impact on their health and their work as well (Jedin and Abidin, 2013). 
This is because international assignments involve significant changes in the job the individual performs and the corporate culture in which responsibilities are executed. It also involves dealing with unfamiliar norms related to the general culture, living conditions, weather, food, healthcare, daily customs, and political system (Li, 2016). People experience stress as psychological and physiological reactions when they are unable to handle the demands of life events, with work-related events, relationships, and finances being the most common stressors for adults (Durant and Laran, 2016, cited in Subramaniam, 2017). Employees can experience stress at work and outside of work for several reasons. Apart from the above-stated effects of stress on expatriate workers and employees generally, a study by (McNulty, 2015) have also attempted to empirically examine the causes and consequences of expatriate divorce. The findings from the study reveal that expatriate marriages end in divorce due mainly because of a core issue in the marriage like alcoholism, mental health problems) and when one or both spouses is negatively influenced by an expatriate culture. At this juncture, it is important to ask; what are the causes of stress for expatriate workers? There have been attempts in the literature to pinpoint some of the factors that cause stress for expatriate workers and employees generally.

Some of the causes of stress that have been identified in literature include; cultural shock, language barriers, the unfamiliarity of the foreign place. The people, the doubts of acceptance by the host country, relationship with the boss or subordinates and separation from the family. Causes of stress i.e. stressors have been classified under the main heading as Job-related stressors (Shah and Muraduzaman, 2013). Specifically, cultural adjustment and shock is the adjustment of expatriate with the job, host country nationals, and to general work and non-work environment. Another important factor that has been identified to be a stressor is Job/Task characteristics and organizational variables which are also believed to affect the expatriate adjustment such as role ambiguity/clarity, role discretion, role overload, and organizational structure and size, (Shah and Muraduzaman, 2013). Furthermore, (Shah and Muraduzaman, 2013) identified a communication problem in line with other studies as a potential stressor for expatriate workers. It was explained that possibilities for communication and interactions are considerably enhanced if expatriates are proficient in the language of the culture in which they are operating. Other stressors that have been identified in the literature is gender issues; gender issue is a stressor for expatriates especially.

The female ones (Jacob, 2004, cited in Shah and Muraduzaman, 2013). It was further explained that women irrespective of their culture face resistance by some men when they try, to advance in their career. Hence, expatriate women need to have to be more skilled and adjusting to foreign culture than their counterparts. The quality of the superior-subordinate relationship acts as a potential stressor for expatriates. Relationships between superiors and subordinates who are most times from different cultures form the significant aspect of multinational organizations effectiveness (Shah and Muraduzaman, 2013). The most vital of all the stressors is the personal stressors especially family issues; family of expatriates also experience stress similar to the culture shock experienced by the expatriates. Adjustment of the expatriate spouse and family to host country may be a potential problem despite affecting the expatriate and may even lead to assignment failure. It is important to note that unlike the expatriate, his/her family does not undergo training which would help in their adjustment in host country especially, the children find themselves strangers in school and face unfamiliarity of the situations but, must cope with all social traumas which can actually cause extreme stress.

Moving across vast oceans or between continents, far from family, community-unity, the country also creates a more deeply felt and unique kind of stress to the expatriates and their families (Shah and Muraduzaman, 2013). In a study in Malaysia conducted by (Razak et al., 2014), the findings from the study reveal that there is a positive and strong correlation between workload and work stress, it was further stressed in the study that there exists a positive and strong relationship between role conflict and work stress. Li, (2016) discussed two individual-level factors that influence expatriate adjustment, while discussing it from two aspects; individual characteristics (including self-efficacy and interpersonal skills) and previous international experience. For the individual characteristics, some of those listed include; the individual's desire to adjust to the new environment, technical or managerial competence, a person's social relation skills orientation, an individual's tolerance for ambiguity or open-mindedness, an individual's self-confidence. Looking at prior international experience in living or working abroad, (Okpara and Kabongo, 2010, cited in Li, 2016) found that prior international experience (working or non-working) experience that expatriates possess is likely to influence their adjustment to their host country, it was further mentioned that previous international work 
experience, such as travelling and studying, are likely to be associated with the extent to which expatriates adjust to foreign cultures.

Effects of Working Terrain and Environment on Psychological Standing of Employee: The working environment plays a significant role in the life, performance, and commitment of the employees. Employment and working conditions have powerful effects on the health of workers (Block, 2010). It has even been mentioned in the literature that there is evidence that work affects the health of the workers whether physically or mentally (Berniell, 2012). The study also found that there is a moderately significant correlation relationship between interpersonal relationship at work and work stress experienced by expatriates in Government link corporations in Malaysia. It was deduced in a study conducted by (Juhl and Fuglsig, 2009) that motivation of any expatriate could be influenced by some factors which are not directly linked to their professional life; such factors are family situation and expatriate communities. Some other factors that have been found to be associated with work stress include workload, role conflict and interpersonal relationship (Razak et al., 2014).

These factors have a greater influence on the psychological well-being of expatriate and those factors are key to expatriate stability in the new work environment. Furthermore, a study by Osman-Gani and Ruckstuhl (2008), cited in Juhl and Fuglsig, 2009) suggested social support as an important means to reduce expatriate job uncertainty and stress in the new work environment. Job Demand control model has shown that Jobs with low levels of worker control and high expenditures of psychosocial effort expose employees to job strain. Job strain leads to less job satisfaction, exhaustion and depression, and in the long run to stress-related illnesses, including cardiovascular disease (Lewchuk et al., 2003), (Adler, 2008, cited in Juhl and Fuglsig, 2009) emphasized how important expatriate families are on their professional life and performance at work especially in the first three months of departing to new job location and further stated that staying beyond this crucial period would have a greater influence on the expatriate success.

Managing Difficulty of Working in a Stressful Environment: Global competition and market demands for corporate management structures demand highly skilled personnel to forge international relationships and create an international corporate presence. International employees often face challenges including adjusting to the different political, economic and cultural environment of the host countries despite career progression and financial benefits (Koteswari and Bhattacharya, 2007). The new environment where expatriates find themselves could be very new to them and have either a positive or negative impact on them. It has been established that stress, either job related or personal, is one of the reasons for expatriate failure resulting into absenteeism, alcohol and drug abuse as well as aggression towards other people within and outside the organization (Koteswari and Bhattacharya, 2007). It has also been said that stress inside and outside of work affect employees productivity and lead to employees disengagement (Subramaniam, 2017). Challenging work in a difficult environment could affect the performance and commitment of employees which eventually affect the goals of the organization (Ashraf et al., 2012) in a study attempted to explore some of the ways to manage and improve employee organizational commitment.

Some of the issues brought up include; goal setting, employee engagement and optimism at the workplace. Managing the difficulty associated with stressful environment and achieving organizational commitment, the study concludes "that organizational commitment can be achieved by correlating goal setting, employee engagement, and workplace optimism in a positive way but the desired result can only be achieved by the effective implementation of all the factors" (Ashraf et al., 2012). Diverse multicultural environment (Misunderstandings in terms of communication, culture, religious practices and social association) and employee performance (or commitment). Expatriate adjustment and work performance are one of the major global challenges business owners, managers and human resource personnel face. As earlier mentioned, the language of a new work environment or duty station is most times different from the home country for many expatriates as well as culture, religious practices and social associations which in most cases have a huge bearing on the performance of employees. As earlier stated one of the major misconceptions and misunderstanding about expatriates is the belief that they are rich and could be happy living.

Their familiar terrain for new places to earn more money which has been dispelled as untrue. Looking at communication, interpersonal relationship is very important to work and promotes daily interaction between 
employees and managers thereby reducing tensions and frustration (Jedin et al., 2013). Lack of communication at the workplace affects employee performance and commitment. In summary, literature has identified a number of factors at the individual and organizational level that affects the performance of employees on the job as well as their level of motivation to be committed or engaged in their duty at the place of work and assignments. Some others have given explanations to these factors including (Alvi, 2017; Albdour et al., 2014; Gujral et al., 2012). Specifically, this study fills the gaps in the literature on the employee engagement in multinational diverse challenging terrain which has not been the focus of many studies in employees' engagement and expatriate literature and would seek to contribute to the literature by studying how the commitment of employees in a diverse environment similar to the study area are affected by the myriad of factors like communication, socio-cultural, social association, stress, work terrain.

\section{Methodology}

Research Method: The research applied a mixed research approach, utilizing both qualitative and quantitative research strategies. This was employed with the intention to provide a deep inquiry and exploration into the research question. It is generally believed that individuals construct reality from their personal and social experiences; hence, to elicit the information required for this research, In-depth Interviews (IDIs) were conducted. 5 In-depth interviews were conducted targeting experts with over 8 years of international experience. The Quantitative aspect of the research involved randomly selected 100 participants from the sample frame of the study and augmented information obtained from the qualitative component of the research. The study location is the United Nations Peace Keeping Mission in Darfur, Sudan, a non-family duty station. The study population consists of 100 respondents from the United Nations Peace Keeping Mission in Darfur, Sudan. The sample population comprised of United Nations African Mission employees who have held their international posts for more than I year. The researcher used Cronbach alpha coefficient value to determine the level of reliability of the questionnaire.

This targeted those who have stayed in their duty stations and have had experienced lived realities on the ground. The sample size for the Qualitative data collection was determined based on the social, economic and demographic characteristics of the respondents while the quantitative data targeted 100 respondents. The data collection tool for the study was an in-depth interview. The in-depth interviews offered the researcher the opportunity to capture rich, descriptive data about people's behavior, attitudes and perceptions, and unfolding complex processes. The tool provided the researcher with the room to probe further and have a deeper insight into the issues in question as well as leading the respondents while keeping opinions unbiased. The researcher also used structured questionnaires in order to elicit information for the respondents and these questionnaires were deployed through the website SurveyMonkey.com. This method enabled the researcher to reach many respondents and the instrument allowed them to respond at their own times. This gives the respondent the opportunity to respond at their own time given, they were engaged in official work.

Validity and Reliability Analysis: The instrument is valid if it measures what is claimed to measure. For any data gathering procedures through questionnaires, content validity is considered as an important technique available to the researcher, it usually refers to the degree to which an instrument actually measures or is specifically related to the trait for which it was designed (Awolusi, 2019; Awolusi \& Atiku, 2019). To ensure the validity of the instrument, the draft questionnaires were presented to the research supervisor for corrections (Awolusi, 2018). Also, the draft was presented to experts in the field of financial management. The suggestions and corrections were incorporated before administering the instrument to the respondents. An instrument is reliable if it measures under the same circumstance what is set out to measure. For this study, questionnaires were administered to the 115 expatriate staff in the duty station. The researcher solicited the consent of the expatriates before administering the questionnaires to ensure a prompt response. The response of all the respondents was treated with the utmost confidentiality.

Method of Data Analysis: The quantitative data were analyzed using both descriptive statistical tools and inferential statistical tools. Specifically, tables and percentages were used to analyze the demographic variables, while Chi-Square statistics was used to test all hypotheses, that is the relationship between employee engagement variables and expatriate's job commitment (Alvi, 2017; Albdour et al., 2014). The qualitative data were analyzed using thematic analysis, the transcriptions were read carefully and theme of 
each subject was properly attended to. Appropriate statistics techniques were chosen based on the nature of the variables of interest. Ethical consideration was built into the study; ethical approval was obtained before the data interview was conducted with the respondents in the study location.

\section{Results and Discussion of Findings}

Demographic Analysis: Table 1 (appendix 1) shows the percentage distribution of the respondents by selected characteristics of the respondents. In the table, it can be seen that about $45 \%$ of the respondents are within the age group 35-44, while another $45 \%$ are in the age group 45-54 and those in the last age group of 55-64 are just 9\%. Males from $67.9 \%$ while females form $32.1 \%$. By continent of birth, $78.6 \%$ of the respondents were born in Africa, about 12\% were born in Asia, $7 \%$ were born in Europe while the remaining $2 \%$ were born in North America. Close to $79.8 \%$ of the respondents are married while $17.8 \%$ are single and $2.4 \%$ are divorced. $87 \%$ of the respondents have children, while $13 \%$ do not have children. The table also presents the level of education of the respondents in which $4.9 \%$ have 3 years of college education, 30.5\% completed graduate school, $47.6 \%$ of the respondents graduated from college, $11 \%$ are high school graduates and $6.1 \%$ attended some graduate school.

\section{Inferential Statistical Analysis}

Table 2: Chi-Square of the Relationship between Employee Commitment and Expatriate's Job Commitment

\begin{tabular}{|c|c|c|c|c|}
\hline \multicolumn{5}{|c|}{ Do you Think the Manager Carries Everyone Alone in Decision Making } \\
\hline & & No & & Yes \\
\hline No & & $6(22.2)$ & & $21(77.8)$ \\
\hline Yes & & $6(20.0)$ & & $24(80.0)$ \\
\hline Others & & $4(20.0)$ & & $16(80.0)$ \\
\hline Statistic & $\mathbf{D F}=2$, & $\chi^{2}=0.0526$ & $p>0.05$ & \\
\hline
\end{tabular}

Table 2 above is the chi-square table used to answer objective 1, in the analysis, being carried along in decision making was used as a proxy for employee disengagement. The first objective was to investigate the effect of employee disengagement on expatriate's job commitment in UNAMID. In the chi-square, based on the p-value calculated which is greater than 0.05 , there is no significant relationship between employee disengagement and expatriate's job commitment in UNAMID. Examining the pattern, majority of the respondents who said the manager carries them along in decision making said that it affects their job commitment while few expatriates said the manager does not carry them along in decision making said it does not affect their job commitment. The analysis in table 1 was also used to achieve objective 1 , satisfaction with treatment at work in terms of salaries, entitlements and benefits were taken as a proxy for employee disengagement, it was found that there was no significant association between treatment at work and expatriate's job commitment with $\mathrm{p}>0.05$. In details, $76 \%$ of those who are not satisfied with their treatment claimed that it would affect expatriate's job commitment. There is, therefore, is no significant relationship between employee disengagement and job commitment of expatriates in UNAMID.

Table 3: Chi-Square of the Relationship between Job Stress and Expatriate's Job Commitment

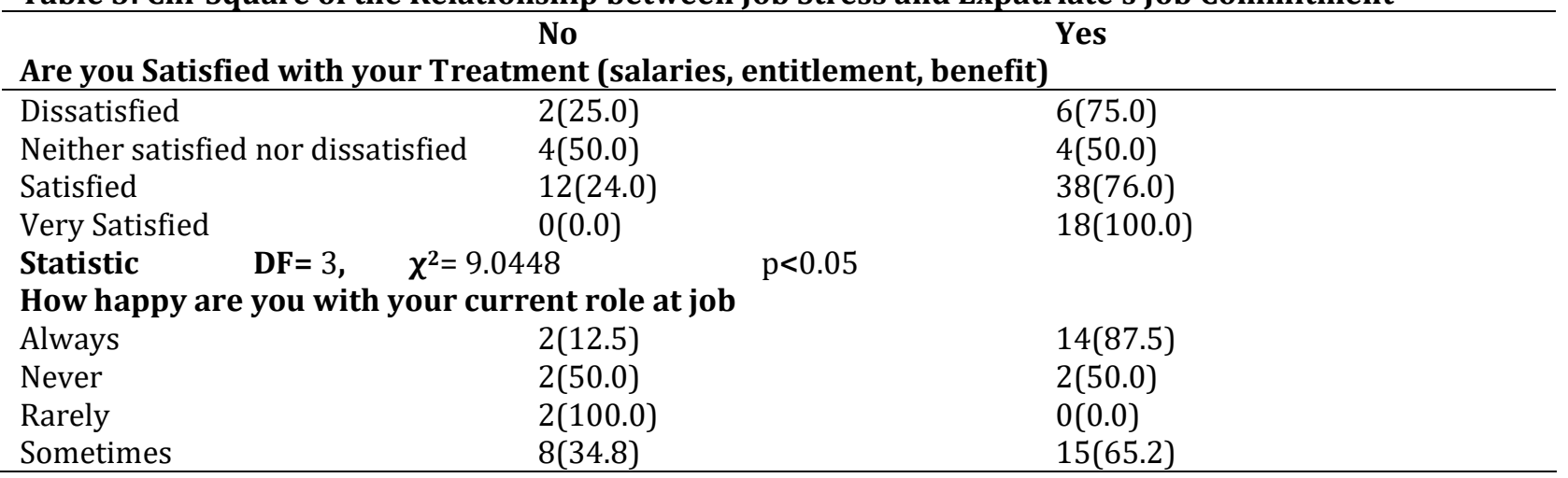




\begin{tabular}{lcccc}
\hline Usually & $4(10.8)$ & & $33(89.2)$ \\
Statistic & DF $=4$, & $\chi^{2}=14.6727$ & $\mathrm{p}<0.05$ & \\
\hline
\end{tabular}

The table above tested the influence of job stress on expatriate's job commitment in UNAMID. Using job satisfaction that may create stress on the job and happiness on the job as a proxy to test to the relationship between job stress and expatriate's job commitment, the study found no significant relationship between job stress and expatriate's job commitment in UNAMID. Specifically, the analysis revealed that satisfaction with treatment at the job is not significantly associated with expatriate's job commitment. In the same vein, happiness with current job role is not significantly associated with the commitment of expatriate's to their job in UNAMID. Hence, we accept the null hypothesis that there is no significant relationship between job stress and expatriate's job commitment to UNAMID.

Table 4: Chi-Square of the Relationship between Working Terrain and Expatriate's Job Commitment

\begin{tabular}{|c|c|c|c|}
\hline \multicolumn{4}{|c|}{$\begin{array}{l}\text { No } \\
\text { Is the Weather Affecting your Work Output }\end{array}$} \\
\hline No & $8(32.0)$ & & $17(68.0)$ \\
\hline Yes & $10(17.5)$ & & $47(82.7)$ \\
\hline Statistic $\quad D F=1$, & $\chi^{2}=2.1198$ & $p>0.05$ & \\
\hline \multicolumn{4}{|c|}{ How are you coping with the new environment } \\
\hline About the same & $10(24.4)$ & & $31(75.6)$ \\
\hline Better & $8(22.9)$ & & $27(77.1)$ \\
\hline Worse & $0(0.0)$ & & $8(100.0)$ \\
\hline Statistic & $\chi^{2}=2.4378$ & $p>0.05$ & \\
\hline
\end{tabular}

Table 3 above relates to the third objective which sought to examine the effect of working terrain on expatriate's job commitment in UNAMID. Looking at the effect of weather on job commitment of the expatriates. It can also be seen from the table that $68 \%$ of those who said the weather was affecting their work output also claimed that it affected their job commitment, while about $18 \%$ of those who said the weather was affecting their work output said it affected their job commitment. The p-value as seen from the table is higher than 0.05 for those who said yes to the weather affecting their work output, and to how they are coping in the new environment. Hence, we accept the null hypothesis that there is no significant association between work terrain and expatriate's job commitment in UNAMID.

Table 5: Chi Square of the Relationship between Communication and Expatriate's Job Commitment

No Yes

How Would You Rate the Communication Chain in UNAMID, From Your Superior to you

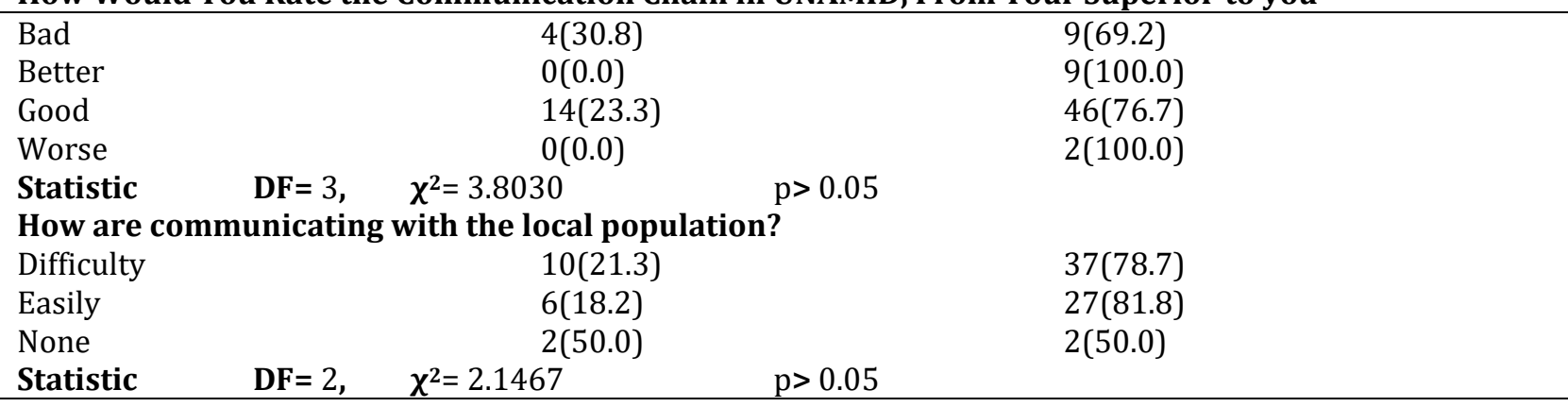

The table above was used to achieve the fourth objective of the study which was to determine the relationship between communication and employee commitment. The first table shows the relationship between the communication chain in UNAMID from superiors and expatriate's job commitment. It was found that there is no significant relationship between communication with superior at workplace and expatriate's job commitment, with a p-value greater than 0.05 . Further details show that majority of people who said the communication chain with their superior is good are committed to their work. 
Table 6: Chi Square of the Relationship between Socio-Cultural Factors and Expatriate's Job Commitment

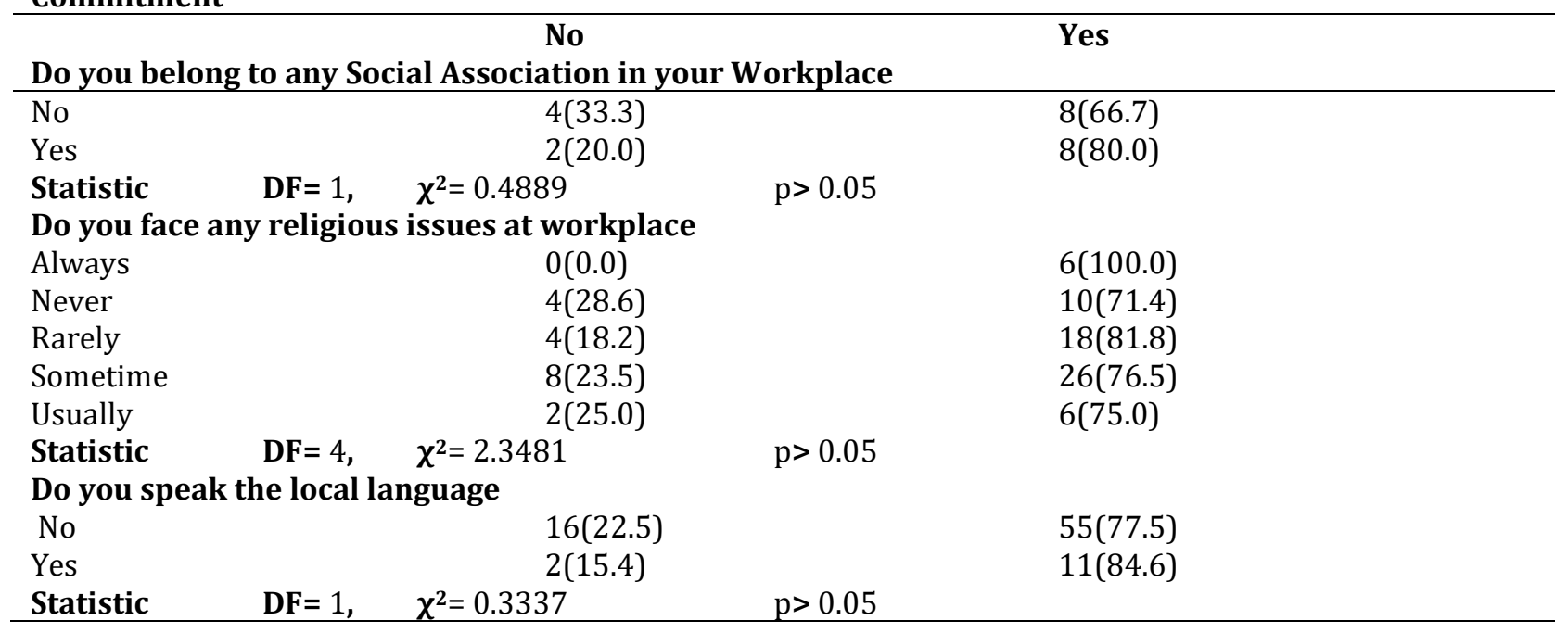

The second table shows communication with the local population and the relationship with employee commitment, there was no significant relationship found between communication with the local population and expatriate's job commitment at p-value greater than 0.05 . In details, $27 \%$ of those who find it easy communicating with the local population are committed to their job and $10 \%$ of those who find it difficult communicating with the local population are not committed to their job. We hereby accept the null hypothesis that there is no significant relationship between communication and expatriate's job commitment in UNAMID. The fifth objective of the study was to examine the influence of socio-cultural factors on expatriate's job commitment in UNAMID. The chi-square analysis presented shows that there is no significant association between belonging to a social association at the workplace and expatriate's job commitment. It can also be seen from the table that $80 \%$ of those who belong to a social association in the workplace are also committed to their work.

Qualitative Study: Findings from participants revealed both negative and positive effects of working at home and working in another country. The participants listed some of the positive effects of working in the home country such as it gives one time to attend to other obligations; reduces stress and enables one to receive more support from family and relatives. On the other hand, working outside has the potential of reducing job performance. Furthermore, findings revealed that working outside the country has a negative effect on workers commitment to work. However, most respondents alluded to the fact that working outside the country provides the opportunity to interact with different people with different expertise thereby increasing organization growth. Majority of the respondents indicated that communication barrier had no effect on their job comment while acknowledging that communication amongst employees is critical in promoting real harmony of interest and teamwork. The study found that the work environment does not have an effect on the expatriates' job commitments as well as performance. Most respondents indicated that socio-cultural factors such as religion do not affect their job commitment.

Discussion of Findings: The study had five specific objectives, the first objective was to assess the influence of employee disengagement on expatriate's job commitment in UNAMID, and this study did not find a significant association between the two variables. These findings echo the findings of (Robertson-Smith and Markwick, 2009) where it was suggested that employees engagement which is something given by employees for the benefit of the organization through commitment and dedication, advocacy, discretionary effort, using talents to the fullest and being supportive of the organization's goal and values has a positive effect on the achievement of the goals of the organization meaning that employees are committed to their duties, thus any unacceptable act either from the management or the superiors could affect the level of commitment from the employees. Also, this study is in contrast to the findings of (Albdour and Altarawneh, 2014), who pointed out that high job engagement and organizational engagement will meaningfully lead to a higher level of 
commitment to duty amongst frontline employees in the study conducted in Jordan. Speaking the local language was also found not to be associated with job commitment among the expatriates.

$84 \%$ of those who said they speak the local language are committed to their work, $78 \%$ of those who said they cannot speak the local language are committed to their work. Hence, we accept the null hypothesis that there is no significant relationship between socio-cultural factors and expatriate's job commitment. A likely explanation for this observed disparity might be due to the fact that this study was conducted among expatriates who might be affected by other factors while the respondents in the Jordan study were not expatriates. In the same vein, (Ashraf et al., 2012) in their study have also identified employee engagement as one of the important factors to increase employee organizational commitment, this assertion from these researchers is in contrast to the findings in this study. A plausible explanation for this might be that the context of this study which is not a company setting likes the other study and which focuses on the expatriates. The findings showed that improved communication and a good working environment have no correlation with staff retention and better performance. This is in contrast to the findings of (Wanjau et al., 2012) in a study of the contribution of motivational management to employee performance in which they pointed out that management motivational variables significantly influenced employee retention in the sampled organizations.

Stress Management at the Workplace: The study found no significant relationship between job stress experienced by the expatriates and their commitment to duty in their workplace (UNAMID). In their study, (Shah and Muraduzaman, 2013) was of the opinion that potential stressors are enveloped in a number ways that eventually affect the performance of the employees, this study however found otherwise that stress is not a factor that affects the performance of the duties of expatriates. To explain this discrepancy, this might be due to the fact that the study was conducted among expatriates earning a reasonably good amount of money to meet their needs and take good care of themselves (Makgati \& Awolusi, 2019; Simwanza \& Awolusi, 2019).

Work Environment and Expatriate's Job Commitment: The study found out that there is no association between working terrain and expatriate's commitment to work in UNAMID. This finding is not in tandem with the outcome of the study conducted in Pakistan by (Khalid et al., 2016) where they pointed out that favourable job conditions affected organizational commitments of the bank workers. It could be explained that the Pakistan study was among workers in a setting that is different from that of the expatriates in UNAMID who are faced with other challenges which might be more than what the bankers in Pakistan who are not expatriates are going through. Contrary to the findings in this study, (Akinyele, 2010) in his study on "the influence of work environment on worker productivity: A case of selected Oil and gas industry in Lagos, Nigeria" found out that conducive work environment stimulates the creativity of workers. Improvement in the work environment and poor working conditions contribute to low productivity of employees. Similar findings were shown in India where they found that organizational climate experience by employees which can be likened to work terrain determined a higher employee engagement contrary to the findings of this study.

Communication at the Workplace: The study found that expatriate's job commitment is not influenced by communication whether within the organization or with outsiders i.e. the local population. Studies have shown that communication affects the performance of expatriates. For instance, (Krishnaveni and Arthi, 2015) submitted that the most predominant factor that highly influences the success of an expatriate is his/her linguistic skills in the host national language.

Socio-Cultural Factors and Expatriate's Job Commitment: The study found that socio-cultural factors do not influence expatriate's job commitment. The findings are in contrast to the findings of (Krishnaveni and Arthi, 2015) where it was concluded in a study of multidimensional factors influencing the effective performance of employees that cultural intelligence is the most influential factor that affects employee performance due to the nature and diversity of a host country. The study also asserted that most of the issues faced by expatriates, especially those influencing their performance, results from a variety of cultural differences experienced by the expatriates both within and beyond the context of their work. (Rose et al., 2010) have also found greater behavioural cultural intelligence to be associated with greater assignment specific performance contrary to the findings in this study. 


\section{Conclusion, Recommendations and Policy Implications}

Conclusion: The study was able to achieve the five specific objectives that were set out at the beginning. The study discovered that socio-cultural issues, communication, employee disengagement, job stress and working terrain were not associated with the performance of expatriates on their jobs in UNAMID. This study concludes that employee disengagement, job stress, working terrain, communication and socio-cultural factors are not associated with expatriate's job commitment in UNAMID. This conclusion is based on an empirical analysis of data collected from respondents in the study area. From a theoretical perspective, the findings of this study have not taken side with any of the theoretical conceptual frameworks that were used to underpin this study, although the finding might not be strong enough to disprove the assertions and submissions of the theories, it can be said that the context of this present study i.e. UNAMID among expatriates, might have played a significant role in the rather surprising findings of this present study.

Recommendations and Implications: This study hereby makes the following recommendation, that managers and human resource experts concerned with these expatriates in the study context and other locations consider factors like a socio-cultural peculiarity of the duty station, communication chain whether between the expatriates and colleagues at work or the locals, working terrain in making provisions that would make these expatriates more comfortable in their new job locations. Organizations or institutions need to make efforts to enhance the level of employee engagement to improve the morale and psychology of the workers. Employee disengagement though not found to be significantly associated with the job performance of the expatriates should be an issue of utmost importance to managers. Work stress that could negatively impact on the psychological and physical health of the expatriates should also be managed through. The sharing of the workload it is recommended that short trips be organized for new expatriates in order to get used to the socio-cultural terrain and familiarize with the context.

In which they would be operating (Okpara and Kabongo, 2011) it is imperative for the organizations employing expatriates to arrange for pre-deployment induction training at the country of origin and in the host country. This will prepare the expatriates to adapt to the new environment (Collings et al., 2011). Expatriates require better health services if they have to contribute meaningfully to the operational effectiveness and therefore organizations need to have health insurance covers and benefit entitlements including home leave, family visits, sick leave days, hardship allowance and rest and recuperation. Security of the expatriates is paramount and organizations need to take measures to ensure security and safety of the expatriates' in line with the international standards within Minimum Operating Residential Security Standards (MORSS). This study has been able to contribute immensely to the existing body of knowledge on employee engagement and performance in the field of human resources by providing an insight into some of the factors associated with employee engagement in a setting that has another dimension to the normal office environment. For practice, human resource managers can apply findings from this study in dealing with situations relating to their expatriate staff and their other staff in terrains like UNAMID.

The factors that have been identified in this study could form the basis of management plans that could help ensure employee engagement and commitment to duties in order to achieve the organization's goals. However, the study had some limitations including; scantiness of literature to really measure the concept of the variable of interest which is employee engagement as a thorough search of literature databases showed that few studies have studied employee engagement especially in the context of this study. The limited understanding of English could not enable me to have in-depth engagement with most of the respondents during individual interviews. In addition, consolidating the findings in English was a major challenge since French is my official language. I addressed this challenge by recording the conversation for repeated reference to make sure that I did not lose the substance of the discussion. Another limitation was the fact that I was researching an organization with which I work and chances of being subjective were very high. I tried to minimize the influence of my opinion by remaining objective and being guided by the structured questionnaires throughout the study. Time was constrained considering the fact that I was at work at the same time I was engaged in data collection and analysis and putting it together. I had to do the study outside the office working hours to ensure that I met the deadline. 
Acknowledgement: This paper is an extracts from a Master of Business Administration thesis at the University of Roehampton, London. Prof. Olawumi .D. Awolusi was the supervisor of the study.

\section{References}

Akinyele, S. T. (2010). The influence of work environment on workers productivity: A case of selected oil and gas industry in Lagos, Nigeria, African Journal of Business Management, 4(3), 299-307.

Albdour, A. A. \& Altarawneh, I. I. (2014). Employee Engagement and Organizational Commitment: Evidence from Jordan, International Journal of Business and Management, 9(2), 192-212.

Alvi, U. (2017). The Effect of Psychological Wellbeing on Employee Job Performance: Comparison between the Employees of Projectized and Non-Projectized Organizations, Journal of Entrepreneurship \& Organization Management, 06(01), 23-35.

Ashraf, Z., Jaffri, A. M., Sharif, M. T. \& Khan, M. A. (2012). Increasing Employee Organizational Commitment by Correlating Goal Setting, Employee Engagement and Optimism at Workplace', European Journal of Business and Management, 4(2), 71-77.

Awolusi, O. D. \& Atiku, O. S. (2019). Business Process Re-Engineering and Profitability in the Nigerian Oil and Gas Industry: The Mediating Influence of Operational Performance, Information Management and Business Review, 11(3), 13-26.

Awolusi, O. D. (2019). Human Capital Development and Economic Growth in BRICS Countries: Controlling for Country Differences, Journal of Economics and Behavioral Studies, 11(4), 1-17.

Awolusi, O.D. (2018) 'Policy and Non-Policy Factors: What Determines Foreign Direct Investments in Africa? Journal of Social and Development Sciences, 9(4), 49-61.

Berniell, M. I. (2012). The Effects of Working Hours on Health Status and Health Behaviors CEMFI-UIMP.

Bhatti, M. A., Sundram, V. P. K. \& Chee Hee, H. (2012). Expatriate Job Performance and Adjustment: Role of Individual and Organizational Factors, Journal of Business and Management, 1(1), 29-39.

Bhuvanaiah, T. \& Raya, R. (2015). Mechanism of Improved Performance: Intrinsic Motivation and Employee Engagement, SCMS Journal of Indian Management, 2(1), 92-97.

Bonache, J. (2005). Job satisfaction among expatriates, repatriates and domestic employees, Personnel Review, $34(1), 110-124$.

Block, S. (2010). Exploring the impact of employment on health disparities, Work and HealthDale Carnegie Training, (2012) What Drives Employee Engagement and Why It Matters, 1-6.

Collings, D. G., Doherty, N., Luethy, M. \& Osborn, D. (2011). Understanding and Supporting the Career Implications of International Assignments, Journal of Vocational Behavior, 78(1), 361-371.

Cropanzano, R. \& Mitchell, M. (2005). Social Exchange Theory: An Interdisciplinary Review, Journal of Management, 31(6), 874-900.

Dajani, M. A. Z. (2015). The Impact of Employee Engagement on Job Performance and Organisational Commitment in the Egyptian Banking Sector, Journal of Business and Management Sciences, 3(5), 138147.

Darwin, J. R. \& Selvaraj, P. C. (2015). The Effects of Workforce Diversity on Employee Performance in Singapore Organisations, International Journal of Business Administration, 6(2), 17-29.

Doyle, C., Kavanagh, P., Metcalfe, O. \& Lavin, T. (8 ${ }^{\text {th }}$ Mars 2005). Health Impacts of Employment': A review: Institute of Public Health in Ireland, 1-24.

Dulye, L., Grossman, D., Quinlan, T. \& Vanstone, C. (2007). The practitioner's guide to essential techniques for employee engagement: tips, tools and practice advice for building a committed workforce, Chicago, Il.: Melcrum Publishing.

Gujral, H. K. \& Jain, I. (2012). Determinants and Outcomes of Employee Engagement: A Comparative Study in Information Technology (IT) Sector, International Journal of Advanced Research in Management and Social Sciences, 2(5), 207-220.

Gupta, G. \& Gupta, A. (2012). International Assignments, Expatriate Adjustment and Perceived Impact of Parent Organization Support, the Business \& Management Review, 3(1), 57-65.

Hack-Polay, D. (2012). When Home Isn't Home - A Study of Homesickness and Coping Strategies among Migrant Workers and Expatriates, International Journal of Psychological Studies, 4(3), 62-72.

Haslberger, A. \& Brewster, C. (2009). Capital Gains: Expatriate Adjustment and the Psychological Contract in International Careers, Human Resource Management, 48(3), 379-397. 
Hijry, H. \& Haleem, A. (2017). Study the Factors That Influence Employees Performance in the Steel Factory, Proceedings of the 2017 International Conference on Industrial Engineering and Operations Management, SaudiArabia: the Tabuk University of Mechanical and Industrial Engineering Department, 899-916.

ILO. (2016). Work Place Stress: A Collective Challenge, International Labour Organisation

Jedin, M. \& Abidin, N. I. Z. (2013). Work Stress Among Expatriate Managers in Malaysia's Government-linked Companies, In The International Conference on Social Science Research, Malaysia: Penang, 665-682.

Juhl, B. \& Fuglsig, S. C. S. (2009). A study on motivational factors influencing the expatriate through the expatriation cycle, B.scB (IM): Aarhus University.

Kang, M. (2014). Understanding Public Engagement: Conceptualizing and Measuring its Influence on Supportive Behavioral Intentions, Journal of Public Relations Research, 26(5), 399-416.

Khalid I. H. K., Naeem, B. \& Khalid, S. (2016). A Study of Factors Affecting Organizational Commitment Among Bank Officers in Pakistan, Journal of Business \& Financial Affairs, 6(1), 25-38.

Koteswari, V. B. \& Bhattacharya, M. S. (2007). Managing Expatriate Stress, Delhi Business Review, 8(1), 89-98

Krishnaveni, R. \& Arthi, R. (2015). An Overview of Multidimensional Factors Influencing Effective Performance of Expatriates, Journal of Contemporary Management, 20(2), 135-147.

Levinson, E. (2007b). Authentic CSR Creates Higher Employee Engagement.

Lewchuk, W., de Wolff, A. King, A. \& Polyani, M. (2003). From Job Strain to Precarious Employment: Health Effects of Precarious, Employment. Just Labour, 3(1), 23-35.

Li-Yueh, L. \& Alfiyatul, Q. (2015). The Effects of Work-Role Demands on Cross-cultural Adjustment and Expatriate Effectiveness: A Meta-analysis, Anthropologist, 22(3), 636-649.

Li, Y. (2016). Expatriate Manager's Adaption and Knowledge Acquisition. Personal Development in MultiNational Companies in China, Zeitschrift für Wirtschaftsgeographie, 60(4), 45-59.

Makgati, M. O. \& Awolusi, O. D. (2019). The Influence of Information Communication Technology (ICT) Integration on Teaching and Learning in South African Schools, Journal of Education and Vocational Research, 10(2), 47-64.

Mawritz, M., Dust, S. \& Resick, C. (2014). Hostile Climate, Abusive Supervision, and Employee Coping: Does Conscientiousness Matter? Journal of Applied Psychology, 99(4), 737-747.

McNulty, Y. (2015). Till stress do us part: the causes and consequences of expatriate divorce, Journal of Global Mobility: The Home of Expatriate Management Research, 3(2), 106-136.

Merry, J. (2013). Aon Hewitt's 2013 Trends in Global Engagement: Where do Organizations Need to Focus Attention? Strategic HR Review, 13(1), 24-31.

Meyer, J. (2017). Has Engagement Had its Day, Organizational Dynamic, 46(2), 87-95?

Mokaya, S. O. \& Kipyegon, J. (2014). Determinants of Employee Engagement in the Banking Industry in Kenya; Case of Cooperative Bank, Journal of Human Resources Management and Labor Studies, 2(2), 187-200.

Njenga, G., Kamau, C. \& Njenga, S. (2015). Factors Affecting Employees' Commitment to an Organization: A Case Study of Jodan College of Technology (JCT), Thika. International Journal of Scientific and Research Publications, 5(10), 76-89.

Nunes, I., Felix, B. \& Prates, L. (2016). Cultural Intelligence, Cross-Cultural Adaptation and Expatriate Performance: A Study with Expatriates Living in Brazil, Revista de Administração, 52(3), 219-232.

Okpara, J. O. \& Kabongo, J. D. (2011). Cross-Cultural Training and Expatriate Adjustment: A Study of Western Expatriates in Nigeria, Journal of World Business, 46(1), 22-30.

Rajasekar, J. \& Renand, F. (2013). Culture Shock in a Global World: Factors Affecting Culture Shock Experienced by Expatriates in Oman and Omani Expatriates Abroad', International Journal of Business and Management, 8(13), 56-75.

Ray Moulik, S. \& Mazumdar, S. (2012). Expatriate Satisfaction in International Assignments: Perspectives from Indian IT Professionals Working in the US, International Journal of Human Resource Studies, 2(3), 59-78.

Rajasekar, J. \& Renand, F. (2013). Culture Shock in a Global World: Factors Affecting Culture Shock Experienced by Expatriates in Oman and Omani Expatriates Abroad, International Journal of Business and Management, 8(13), 144-160.

Rashid, H. A., Asad, A. \& Ashraf, M. M. (2011). Factors Persuading Employee Engagement and Linkage of EE to Personal and Organizational Performance, Interdisciplinary Journal of Contemporary Research in Business, 3(5), 98-108. 
Ray Moulik, S. \& Mazumdar, S. (2012). Expatriate Satisfaction in International Assignments: Perspectives from Indian IT Professionals Working in the US, International Journal of Human Resource Studies, 2(3), 59-79.

Razak, M. I. M., Ibrahim, Z., Ridzuan, A. R., Talib, A. H. \& Kedin, N. A. (2014). The Dimensions Of Work Stress Among Expatriates In Government Link Corporation-An Overview, Journal of Economics and Sustainable Development, 5(12), 23-28.

Robertson-Smith, G. \& Markwick, C. (2009). Employee Engagement: A review of current thinking. Mantell Building, University of Sussex Campus, Brighton BN1 9RF, UK: Institute for Employment Studies.

Rose, R., Sri Ramalu, S., Uli, J. \& Kumar, N. (2010). Expatriate Performance in International Assignments: The Role of Cultural Intelligence as Dynamic Intercultural Competency, International Journal of Business and Management, 5(8), 76-85.

Shah, M. G. H. \& Muraduzaman, M. (2013). How Expatriate Stress Can Be Released Through Strategies'? International Journal of Scientific \& Engineering Research, 4(6), 2001-2006.

Shea, T., Pettit, T. \& De Cieri, H. (2011). Work environment stress: The impact of the physical work environment on psychological health, A Snapshot Review: Australian Centre for Research in Employment and Work (ACREW).

Siegrist, J. (1996). Adverse Health Effects of High-effort/Low-reward Conditions, Journal of Occupational Health Psychology, 1(1), 27-41.

Simwanza, M. M. \& Awolusi, O. D. (2019). Customer Experience Monitoring: A Study of Zambian Banks', Journal of Education and Vocational Research, 10(2), 1-17.

Soldati, P. (2007). Employee engagement: what exactly is it? Management Issues.

Subramaniam, K. G. (2017). Strategies for Reducing Employee Stress and Increasing Employee Engagement, Doctorate, Walden University.

Tahir, M., Yousafzai, I. K. Jan, S. \& Hashim, M. (2014). The Impact of Training and Development on Employees Performance and Productivity, International Journal of Academic Research in Business and Social Sciences, 4(4), 86-98.

UNOPS. (2016). Non-Family Duty Stations (NFDS) and Related Entitlements.

Wanjau, K. N., Muiruri, B. W. \& Ayodo, E. (2012). Factors Affecting Provision of Service Quality in the Public Health Sector: A Case of Kenyatta National Hospital, International Journal of Humanities and Social Science, 2(13), 114-126.

Zainol, H., Wahid, A. M. A., Ahmad, A. C., Tharim, A. H. A. \& Ismail, N. (2014). The Influence of Work Adjustment of Malaysian Expatriate Executives in Malaysian Construction Companies Overseas, E3S Web of Conferences, 3(1), 1020-1039.

\section{Appendix 1}

Table 1: Percentage Distribution of Respondents Characteristics and Responses to Question on the Questionnaire

\begin{tabular}{lll}
\hline Variables & Frequency & Percentage \\
\hline Age & & \\
$35-44$ & 49 & 45.4 \\
$45-54$ & 49 & 45.4 \\
$55-64$ & 10 & 9.2 \\
Sex & & \\
Female & 27 & 32.1 \\
Male & 57 & 67.9 \\
Continent of birth & & \\
Africa & 66 & 78.6 \\
Asia & 10 & 11.9 \\
Europe & 6 & 7.1 \\
North America & 2 & 2.4 \\
Marital status & 2 & \\
Divorced & 67 & 2.4 \\
Married & 15 & 79.8 \\
Single & & 17.8 \\
\hline
\end{tabular}




\begin{tabular}{lll}
\hline Do you have any children & 11 & 13.1 \\
No & 73 & 86.9 \\
Yes & 4 & \\
Level of Education & 25 & 4.9 \\
3 years of college & 39 & 30.5 \\
Completed graduate school & 9 & 47.6 \\
Graduated from college & 5 & 11.0 \\
Graduated from high school & & 6.1 \\
Some graduate school & 2 & \\
Which division are you & 44 & 2.5 \\
Military & 8 & 55.0 \\
Mission support & 26 & 10.0 \\
Police & & 32.5 \\
Substantive & 6 & 7.1 \\
Years of experience & 5 & 6.0 \\
4-5 years & 73 & 86.9 \\
Less than one year & & \\
Over 5 years & &
\end{tabular}

